\title{
FAKTOR-FAKTOR YANG MELATARBELAKANGI MOTIVASI SESEORANG UNTUK MENGGUNAKAN SUNTIKAN SILICONE CAIR DI MALANG TAHUN 2001
}

\section{FACTORS MOTIVATING A PERSON TO USE LIQUID SILICONE INJECTION IN MALANG 2001}

\author{
Asmika*, Chusnul Chuluq*, Catur Suci Sutrisnani** \\ * Laboratororium IKM-KP Fakultas Kedokteran Unibraw Malang \\ ${ }^{* *}$ Program Studi Dokter Fakultas Kedokteran Unibraw Malang
}

\begin{abstract}
Recently it has been reported that some women have suffered from illness complication as the effect of the use the liquid silicone to beautify themselves. Knowledge deprivation and eagerness to achieve complete beauty in an easy and cheap way makes them undertake a short cut which is getting the injection. The research is intended to know some factors underlying a person's motivation to use liquid silicone injection in Malang in 2001. The research was a descriptive cross sectional method. The population was person who use liquid silicone injection in Malang 2001, this assume were 20 persons during the research (June - December 2001). This research showed that 15 respondents (75\%) of the samples knew the benefits of liquid silicone injection but did not know the effect of the injection, the education of this respondents were secondary and tertiary level 13 respondents (65\%), 6 respondents (30\%) of the sample working as beauticians, 6 respondents (30 \%) of the samples having salary Rp. 250.000,00 - Rp.500.000,00 per month, 9 respondents (45\%) of the samples feeling more beautiful and self confident after getting liquid silicone injection, 6 respondents (30\%) of the samples getting family permission, 12 respondents (60\%) of the samples having a social network to use the injection, 5 respondents (25\%) of the samples getting secondary health services and 4 respondents (20\%) of the samples getting tertiary health services and 12 respondents (60\%) of the samples always following trend of beauty style. The external factors are more dominant than internal factors to motivate a person to use liquid silicone injection to beautify them selves in Malang 2001. It suggests that the result of this research can be used as a health upgrading material especially for the users of cosmetics and the beauty saloons offering the liquid silicone injection.
\end{abstract}

Key words: Motivation, Liquid Silicone Injection

\section{PENDAHULUAN}

Akhir - akhir ini banyaknya pemberitaan media masa tentang kasus - kasus komplikasi akibat suntikan silicone cair yang sebagian besar dialami oleh wanita. Sebelumnya di Indonesia tidak pernah dilaporkan dan tidak didapatkan data jumlah penderita akibat suntikan silicone cair yang dilakukan oleh orang yang tidak mempunyai wewenang, sehingga hal ini menyulitkan tindakan investigasi terhadap peredaran silicone cair (1).

Berdasarkan laporan dari Rumah Sakit dr. Saiful Anwar (RSSA) Malang pada bulan April 2001 ada kasus seorang wanita pengguna jasa suntikan silicone cair yang di diagnosa menderita silikonoma, kemudian dilakukan operasi pada tanggal 18 April 2001; Pada bulan September 2001 RSSA juga menangani 2 pasien akibat efek samping suntik silicone cair yang masing-masing telah menyuntik hidungnya dengan silicone cair, dan seorang laki-laki yang menyuntik alat kelaminnya dengan silicone cair $(2,3)$.

Di R.S. dr. Soetomo Surabaya dilaporkan bahwa

Jurnal Kedokteran Brawijaya, Vol. XXI, No.2, Agustus 2005 Korespondensi: Asmika; Laboratorium IKM-KP FK Unibraw Malang; Jl. Veteran Malang 65145; telp. (0341) 580993 seorang waria plus PSK (Pekerja Seks Komersial) telah menggunakan jasa suntik silicone cair di payudaranya sebanyak empat kali, dan mengalami dilatasi payudara ke samping dan ruptur, sehingga harus menjalani operasi (4).

Di Solo juga dilaporkan bahwa seorang istri mantan pejabat Solo menggunakan jasa suntik silicone di pipinya, dan setelah empat bulan berjalan mulai terlihat lebam di bekas suntikan tersebut hingga akhirnya menjadi luka. Begitu pula dengan wanita lain di Solo yang menggunakan jasa suntikan silicone di hidung, bibir dan dagunya dalam waktu beberapa hari, bibirnya tertarik keatas hingga mendekati hidungnya dan ada benjolan sebesar kelereng di permukaan dagu dan hidungnya $(5,6)$.

Pada tahun 2004 di Jakarta juga terdapat korban yaitu seorang mahasiswi, yang hari Sabtu pada tanggal 7 Agustus 2004 lalu mencoba memperbesar payudaranya lewat suntikan dengan cairan yang menurut penyuntiknya sebagai kolagen (7).

Dengan banyaknya berita mengenai silicone cair dan efek samping yang ditimbulkan baik secara langsung maupun tidak langsung, maka akan menimbulkan keresahan masyarakat pada umumnya dan pengguna jasa suntik silicone pada khususnya $(8,9)$. Tujuan dari penelitian 
ini adalah untuk mengungkap faktor faktor yang melatar belakangi motivasi seseorang dalam untuk menggunakan suntikan silicone cair. Hasil penelitian ini diharapkan dapat sebagai informasi bagi pihak pelayanan kesehatan dalam penyusunan perencanaan pelayanan kesehatan secara komprehensif dan holistik terhadap pengguna jasa suntikan silicon cair, mengingat beratnya efek yang dapat ditimbulkan.

\section{METODE}

Penelitian ini merupakan penelitian deskriptif observasional dengan pendekatan Cross sectional.Sampel sejumlah 20 orang responden dengan metode non randomise sampling (qouta sampling) pada periode Juni sampai Desember 2001. Instrumen Penelitian adalah quisioner, bentuk terbuka dan tertutup dengan tehnik wawancara.

\section{HASIL PENELITIAN}

Dari hasil penelitian didapatkan gambaran terhadap karakteristik responden diantaranya adalah berdasarkan jenis kelamin terbanyak pada perempuan sebesar 11 (55 $\%$ ) orang dan terbanyak kedua adalah waria terbanyak 7 (35\%) orang; Usia terbanyak adalah kelompok yang berusia 31-40 tahun sebanyak 10 (50\%) responden; Responden yang terbanyak berasal dari suku Jawa sebanyak 18 $(90 \%)$ responden.

Distribusi responden berdasarkan agama diperoleh $16(80 \%)$ responden beragama Islam, sedangkan yang beragama non Islam sebanyak 4 orang $(20 \%)$. Berstatus menikah yang terbanyak telah menikah sebanyak $10(50 \%)$ responden.

Diketahui bahwa responden yang bertempat tinggal di Kodya Malang sebanyak 16 orang (80\%), sedangkan yang tertempat tinggal di Kabupaten Malang sebanyak 4 orang $(20 \%)$.

Tingkat Pendidikan responden yang tidak tamat SD sampai tamat SLTP sebanyak 7 (35\%) responden, sedangkan yang memiliki tingkat pendidikan menengah sebanyak $14(65 \%)$ responden. Pekerjaan responden terbanyak adalah bekerja di swasta sebagai pegawai salon kecantikan sebanyak $6(30 \%)$ responden, dan terbanyak kedua adalah pedagang sebanyak $5(25 \%)$ responden. Penghasilan responden didapatkan gambaran bahwa responden terbanyak penghasilannya tiap bulan antara $\mathrm{Rp}$. $250.000,00$ - 500.000,00 sebanyak $6(30 \%)$ responden, sedangkan terbanyak kedua adalah berpenghasilan antara Rp.750.000,00 sampai Rp. 1.000.000,00 sebanyak 5 (25\%) responden.
Tabel 1. Distribusi Keikutsertaan Responden berdasarkan Tempat Penyuntikan dan pemberian Jasa Layanan

\begin{tabular}{lcc}
\hline \multicolumn{1}{c}{ Tempat } & $\boldsymbol{\Sigma}$ & $\%$ \\
\hline Rumah & 5 & 25 \\
\hline Salon & 11 & 55 \\
\hline Lain-lain & 4 & 20 \\
\hline \multicolumn{1}{c}{ Total } & 20 & 100 \\
\hline \multicolumn{1}{c}{ Penyuntik } & $\boldsymbol{\Sigma}$ & $\%$ \\
\hline Profesi kesehatan & 0 & 0 \\
\hline Non profesi kesehatan & 20 & 100 \\
\hline \multicolumn{1}{c}{ Total } & 20 & 100 \\
\hline
\end{tabular}

Pada Tabel 1. Keikutsertaan Responden untuk Menggunakan Jasa Suntik Silicone Cair diperoleh data bahwa hal-hal berikut ini: gambaran mengenai tahun penyuntikan mulai meningkat banyak yaitu tahun 1998 sebanyak 7 (35\%) responden merupakan tahun terbanyak responden mengikuti suntik silicone cair. Sedangkan pada tahun 1999 responden yang suntik silicone cair sebanyak 4 $(20 \%)$ responden dan tahun 2000 responden yang suntik silicone cair sebanyak $5(25 \%)$ responden. Dari data ini menunjukkan bahwa pengguna suntik silicone cair meningkat sekitar tahun 1998, 1999, dan 2000; Tempat penyuntikan silicone cair terbanyak dilakukan di salon kecantikan sebanyak 11 (55\%) responden, lain-lain adalah penyuntikan dilakukan di tempat perkumpulannya yaitu di tempat senam dan tempat Iwama (45\%). Penyuntik silicone cair dilakukan oleh non profesi kesehatan sebanyak 20 $(100 \%)$ responden. Biaya suntik silicone cair per spet terbanyak yaitu Rp. $100.000,00$ per spet sebanyak 9 (45\%) responden.

Tabel 2. Distribusi Pengetahuan Responden terhadap Kegunaan dan Efek Samping Suntikan Silicone Cair

\begin{tabular}{lcc}
\hline Kegunaan silicone cair & $\boldsymbol{\Sigma}$ & $\%$ \\
\hline Tahu & 17 & 85 \\
\hline Tidak tahu & 3 & 15 \\
\hline \multicolumn{1}{c}{ Total } & 20 & 100 \\
\hline Efek samping & $\boldsymbol{\Sigma}$ & $\%$ \\
\hline Tahu & 2 & 10 \\
\hline Tidak Tahu & 15 & 75 \\
\hline \multicolumn{1}{c}{ Total } & 17 & 85 \\
\hline \multicolumn{1}{c}{}
\end{tabular}

Dari Tabel 2. diketahui responden terhadap suntik silicone cair. Responden yang mengetahui kegunaan dari suntik silicone cair untuk merubah bentuk tubuh dan kosmetik terbanyak sebesar 17 orang (85\%), yang mengetahui kegunaan suntik silicone cair dan keuntungan suntik silicone cair sebesar 12 orang (60\%), sedangkan responden yang hanya mengetahui keuntungan suntik silicone cair tapi 
tidak mengetahui efek samping suntik silicone cair sebanyak 15 orang $(75 \%)$.

Tabel 3. Distribusi Sumber Informasi Mengenai Penyuntikan Silicone Cair

\begin{tabular}{ccc}
\hline Sumber informasi & $\boldsymbol{\Sigma}$ & $\%$ \\
\hline Profesi kesehatan & 0 & 0 \\
\hline Non profesi kesehatan & 20 & 100 \\
\hline Total & 20 & 100 \\
\hline
\end{tabular}

Pada Tabel 3. Sumber Informasi Mengenai Penyuntikan Silicone Cair didapatkan gambaran bahwa sumber informasi mengenai penyuntikan silicone cair dari non profesi kesehatan sebanyak 20 (100\%) responden.

Tabel 4. Distribusi Motivasi atau Dorongan Responden dari Keluarga atau teman untuk Mengikuti Suntik Silicone Cair

\begin{tabular}{|c|c|c|}
\hline Didukung keluarga & $\Sigma$ & $\%$ \\
\hline Ya & 6 & 30 \\
\hline Tidak & 7 & 35 \\
\hline Lain-lain & 7 & 35 \\
\hline Total & 20 & 100 \\
\hline Dukungan dari teman & $\Sigma$ & $\%$ \\
\hline $\mathrm{Ya}$ & 9 & 45 \\
\hline Tidak & 0 & 0 \\
\hline Lain-lain & 11 & 55 \\
\hline Total & 20 & 100 \\
\hline
\end{tabular}

Pada Tabel 4. Motivasi Responden untuk mengikuti Suntik Silicone Cair berasal dari keluarga sebanyak 6 orang $(30 \%)$, terutama dari suami untuk responden yang sudah menikah. Sedangkan responden yang tidak mendapat dukungan dari keluarga sebanyak 7 orang (35\%) adalah waria sedangkan sisanya sebanyak 7 orang $(35 \%)$ yang tidak meminta ijin keluarga dan yang ingin mengikuti suntik silicone atas keinginan diri sendiri. Responden mengikuti program suntik silicone cair mendapatkan motivasi dari teman sebanyak 9 orang (45\%) dan lain-lain sebanyak 11 orang $(55 \%)$. Responen yang mengatakan bahwa ada keterkaitan antara mengikuti suntik silicone cair dengan pekerjaannya sebanyak 11 orang (55\%); ada keterkaitan antara mengikuti suntikan silicon cair dengan komunitas atau perkumpulan yang diikuti seperti Iwama, club senam, arisan dan sebagainya sebanyak 14 orang (70\%); Ada keterkaitan antara mengikuti program suntik silicone cair dengan penawaran jasa suntik silicone cair sebanyak 20 orang $(100 \%)$.
Tabel 5. Distribusi Responden Terhadap Penampilan Setelah Suntik Silicone dan Tren Kecantikan

\begin{tabular}{|c|c|c|}
\hline Mengikuti tren & $\Sigma$ & $\%$ \\
\hline $\mathrm{Ya}$ & 12 & 60 \\
\hline Tidak & 8 & 40 \\
\hline Total & 20 & 100 \\
\hline
\end{tabular}

Pada Tabel 5. Sikap responden terhadap suntik silicone cair untuk mengikuti tren kecantikan ada sebanyak $12(60 \%)$ responden.

Tabel 6. Distribusi Perilaku Responden menurut Kebiasaan Pergi ke Salon Kecantikan

\begin{tabular}{lll}
\hline \multicolumn{1}{c}{ Value } & $\boldsymbol{\Sigma}$ & $\%$ \\
\hline Senang & & \\
\hline - Lebih cantik & 1 & 5 \\
\hline - Lebih percaya diri & 8 & 40 \\
\hline - Lebih cantik dan percaya diri & 9 & 45 \\
\hline Tidak senang & 2 & 10 \\
\hline Total & 20 & 100 \\
\hline Kebiasaan ke salon/ bulan & $\boldsymbol{\Sigma}$ & $\%$ \\
\hline Ya & & \\
\hline - Satu kali & 8 & 40 \\
\hline - Dua kali & 1 & 5 \\
\hline - Lebih atau sama dengan tiga kali & 8 & 55 \\
\hline Tidak & 0 & 0 \\
\hline Total & $\mathbf{2 0}$ & $\mathbf{1 0 0}$ \\
\hline
\end{tabular}

Responden setelah mengikuti suntik silicone cair, merasa lebih cantik dan lebih percaya diri sebanyak 9 $(45 \%)$.

Dari Tabel 6. di dapatkan gambaran mengenai perilaku responden atau kebiasaan untuk pergi ke salon kecantikan tiap bulan. Pergi ke salon satu kali tiap bulan sebanyak 8 orang $(40 \%)$ dan responden yang ke salon lebih dari tiga kali tiap bulan sebanyak 8 orang (40\%).

Tabel 7. Distribusi Pelayanan Kesehatan Tingkat Primer tentang Suntik Silicone Cair

\begin{tabular}{|c|c|c|}
\hline Primary Prevention & $\Sigma$ & $\%$ \\
\hline Ya & 0 & 0 \\
\hline Tidak & 20 & 100 \\
\hline Total & 20 & 100 \\
\hline
\end{tabular}

Dari Tabel 7. Pelayanan kesehatan tingkat primer dalam upaya promotive dan preventif tentang pengikutikan suntik silicone cair adalah $0 \%$. 
Tabel 8. Distribusi Pelayanan Kesehatan Tingkat Sekunder terhadap Suntik Silicone Cair

\begin{tabular}{|c|c|c|}
\hline Secondary Prevention & $\Sigma$ & $\%$ \\
\hline $\mathrm{Ya}$ & 5 & 25 \\
\hline Tidak & 15 & 75 \\
\hline Total & 20 & 100 \\
\hline
\end{tabular}

Sedangkan dalam Tabel 8. pelayanan kesehatan tingkat sekunder menemukan kasus akibat efek samping suntik silicone cair sebanyak 5 (25\% responden.

Tabel 9. Distribusi Pelayanan Kesehatan Tingkat Tersier terhadap Suntik Silicone Cair

\begin{tabular}{|c|c|c|}
\hline Tertiary Prevention & $\Sigma$ & $\%$ \\
\hline Ya & 4 & 20 \\
\hline Tidak & 16 & 80 \\
\hline Total & 20 & 100 \\
\hline
\end{tabular}

Dalam Tabel 9. pelayanan kesehatan tingkat tersier untuk responden yang telah terkena efek samping silicone cair sebanyak $4(20 \%)$ responden.

\section{DISKUSI}

Dari hasil penelitian bahwa $11(55 \%)$ responden adalah wanita, 7 (35\%) menamakan dirinya waria dan 2 $(10 \%)$ adalah laki-laki. Hal ini menunjukkan bahwa tidak hanya kaum waria saja yang mengikuti suntik silicone cair untuk merubah bentuk bagian tubuhnya dengan alasan agar penampilannya seperti wanita, tetapi juga kaum wanita sendiri ingin merubah bentuk bagian tubuhnya menjadi seperti yang diinginkan yakni untuk mempercantik diri maupun meningkatkan kepercayaan diri. Begitu pula kaum laki-laki, mereka mempunyai tujuan tertentu dengan ikut suntik silicone cair. Pada penelitian ini didapatkan bahwa seorang responden laki-laki melakukan penyuntikan di alat genetalianya yang berkaitan dengan perilaku seksual dan seorang responden laki-laki yang lain suntik silicone cair di hidungnya dengan tujuan untuk merubah penampilan agar kelihatan lebih tampan.

Dari $18(90 \%)$ responden adalah suku Jawa, sedangkan suku Sunda $1(5 \%)$ dan WNI keturunan sebesar $1(5 \%)$. Hal ini menunjukkan bahwa pengguna suntik silicone cair di kota Malang sebagian besar adalah suku Jawa. Sedangkan status pengguna suntik silicone cair di Malang adalah $10(50 \%)$ sudah menikah, 8 (40\%) belum menikah, hal ini banyak didominasi oleh kaum waria Malang dan 2 $(10 \%)$ adalah berstatus janda. Responden yang sudah menikah berkaitan dengan motivasi yang berasal dari isteri atau suami. Sedangkan responden yang belum menikah berkaitan dengan motivasi dari dirinya sendiri dan atau teman -temannya.
Tahun penggunaan suntik silicone oleh responden berdasarkan pengakuannya, terdapat 1 responden atau $5 \%$ menyatakan telah menggunakan suntik silicone pada tahun 1989, hal ini menunjukkan bahwa suntik silicone cair sudah merebak pada tahun 1989 tepatmya 13 tahun yang lalu, dimana menurut salah satu sumber daftar pustaka kami menyatakan bahwa pengguna jasa suntik silicone cair di salon-salon kecantikan kemungkinan adalah jenis industrial atau silicone cair medical grade yang telah dilarang peredarannya sejak tahun 1970, tetapi masuk indonesia secara ilegal (4). Dari responden juga didapatkan pengakuan menggunakan suntik silicone cair pada tahun 1993, 1995, 1997, masing-masing sebesar 1 (5\%), sedangkan pada tahun 1998 jumlah responden yang mengaku menggunakan suntik silicone cair sebanyak 7 (35\%), angka ini merupakan angka tertinggi dari jumlah responden yang menggunakan suntik silicone cair, kemungkinan besar pada tahun 1998 suntik silicone cair menjadi tren di Malang pada khususnya dan di Indonesia pada umumnya. Pada tahun 1999 sebanyak 4 (20\%), dan responden yang terakhir mengaku menggunakan suntik silicone cair pada tahun 2000 sebanyak 5 (25\%). Hal ini menunjukkan pada tahun 1998, 1999, 2000 sosialisasi suntik silicone cair untuk merubah bagian bentuk tubuh sudah meluas dan menjadi tren, hal ini karena promosi dan persuasi untuk mengikuti suntik silicone cair semakin meluas dan meningkat dari tahun sebelumnya.

Tempat penyuntikan silicone cair kebanyakan di salon-salon kecantikan sebesar $11(55 \%)$ responden dan secara otomatis dilakukan oleh non profesi kesehatan sebanyak $100 \%$, selain itu dari $5(25 \%)$ responden mengaku didatangi ke rumahnya dan ditawari suntik silicone cair dengan biaya terjangkau. Hal ini merupakan salah satu motivasi bagi responden untuk mengikuti suntik silicone cair dan dapat memperoleh apa yang diinginkan untuk tampil lebih cantik, menarik dan percaya diri.

Sedangkan tingkat pendidikan responden didapatkan $1(5 \%)$ yang tidak tamat SD, $3(15 \%)$ tamat SD, $3(15 \%)$ tamat SLTP, $11(55 \%)$ tamat SLTA, dan $2(10 \%)$ perguruan tinggi. Tingkat pendidikan seseorang menentukan sosial ekonomi seseorang yang bisa mempengaruhi kondisi kesehatan seseorang. Dari hasil penelitian rata-rata tingkat pendidikan responden tergolong menengah walaupun ada yang tidak tamat dan tamat SD sebanyak. Tingkat pendidikan ini menentukan kondisi intelektual seseorang untuk berpikir secara kritis dalam mengambil keputusan sebelum bertindak atau memilih sesuatu sebelum melakukannya.

Pekerjaan responden sangat bervariasi namun responden terbanyak adalah mereka yang bekerja di salonsalon kecantikan yaitu sebesar 6 (30\%) sedangkan sebagai pedagang sebanyak $5(25 \%)$ responden, hal ini jelas ada keterkaitan antara suntik silicone cair dengan pekerjaan 
responden., karena mereka ingin tampil lebih menarik untuk meningkatkan jumlah pengunjung yang datang ke salon kecantikannya maupun konsumen Sedangan sebanyak 4 $(20 \%)$ responden adalah mereka yang bekerja di perusahaan swasta mengatakan tidak ada kaitannya antara suntik silicone dan pekerjaannya, tapi mereka mengikuti suntik silicone karena perkumpulan yang mereka ikuti. Hal ini tidak berbeda jauh dengan $2(10 \%)$ responden berstatus ibu rumah tangga, mereka menjawab bahwa keikutsertaan mereka untuk suntik silicone berhubungan dengan perkumpulan yang mereka ikuti seperti perkumpulan senam maupun arisan. Sedangkan untuk pegawai negeri, penjahit, dan pramuniaga masing-masing $1(5 \%)$ responden. Penghasilan seseorang dari mereka bekerja atau suami mereka bekerja berperan penting dalam keikutsertaan mereka untuk suntik silicone cair. Jadi baik pekerjaan maupun social network atau perkumpulan berperan untuk memotivasi responden untuk mengikuti program suntik silicone cair. Namun disini yang tampak lebih banyak berkaitan dengan motivasi responden untuk suntik silicone cair adalah social network atau perkumpulan yang diikuti oleh responden seperti hasil penelitian dalam Tabel 2. Pengetahuan responden tentang silicone cair menjadi salah satu perhatian peneliti, karena berdasarkan hasil penelitian didapatkan 17 (85\%) responden hanya mengetahui kegunaan dan keuntungan silicone cair dari penyuntik yang bukan profesi kesehatan, yang dapat merubah bentuk bagian tubuh sesuai keinginan dengan tujuan untuk tampil lebih cantik, lebih menarik, dan lebih percaya diri tanpa mengetahui efek samping yang akan ditimbulkan kelak. Sedangkan $3(15 \%)$ responden menjawab tidak tahu kegunaan silicone cair, mereka mengikuti suntik silicone cair hanya karena mengikuti temannya saja. Dari 17 responden yang mengetahui kegunaan suntik silicone cair didapatkan $15(75 \%)$ responden tidak mengetahui efek samping silicone cair, sedangkan hanya $2(10 \%)$ responden tahu efek samping dari suntik silicone cair tetapi mereka tetap memutuskan untuk suntik silicone cair karena faktor motivasi dari dalam dirinya lebih berperan dibanding pengetahuan ditambah bukti-bukti temannya yang telah disuntik silicone cair tidak atau belum menimbulkan efek samping. Dasar pengetahuan responden mengenai suntik silicone hanya untuk kosmetik saja, kemungkinan mereka hanya terobsesi untuk menjadi lebih cantik, lebih percaya diri dan lebih menarik. Kemungkinan efek samping yang ditimbulkan dari suntik silicone cair juga bisa karena teknis penyuntikan yang tidak aseptik karena jarum yang dipakai berulang kali pada orang yang berlainan hal ini karena penyuntik bukanlah dari profesi kesehatan

Data yang menunjukkan pelayanan kesehatan tingkat primer sebanyak $0 \%$, artinya dari pihak pelayanan kesehatan tidak pernah mengadakan upaya penyuluhan atau pendidikan masyarakat mengenai suntik silicone cair dan efek samping yang ditimbulkannya. Pelayanan kesehatan masih bersifat kuratif, pelayanan kesehatan menemukan kasus akibat efek samping suntik silicone cair (pelayanan kesehatan tingkat sekunder) sebesar $5(25 \%)$ orang yang termasuk dalam responden peneliti, pelayanan kesehatan itu berupa pengobatan atau operasi debulking dan menjalani rehabilitasi di Rumah Sakit Dr. Syaiful Anwar Malang (lihat Tabel 9). Sedangkan pelayanan kesehatan tingkat tersier yaitu untuk rehabilitasi pasien atau responden baik itu rehabilitasi fisik maupun mental atau psikis akibat efek samping suntik silicone cair sebesar 4 (20\%) responden, jumlah ini berbeda dari pelayanan kesehatan tingkat sekunder dikarenakan satu orang responden atau pasien itu langsung pulang dan tidak melakukan rehabilitasi medik. Hal-hal seperti diatas seharusnya tidak terjadi jika responden sebelum mengikuti suntik silicone cair itu memanfaatkan pelayanan kesehatan tingkat primer dengan cara berkonsultasi dengan tenaga kesehatan maupun upaya dari pihak pelayanan kesehatan sendiri secara aktif mengantisipasi masalah penggunaan suntik silicone cair ini dengan penyuluhan kepada masyarakat tentang suntik silicone cair dan efek sampingnya serta membuat peraturan secara legal tentang larangan praktik penggunaan suntik silicone cair bagi pihak-pihak yang tidak berwenang seperti salon-salon kecantikan yang notabene mereka hanya ingin berbisnis dan mendapatkan keuntungan yang sebanyakbanyaknya tanpa memperhatikan efek samping yang dapat ditimbulkan dari suntik silicone cair tersebut. Hal tersebut dijelaskan oleh David (2001) dan Setiamihardja S (2004) yang menyatakan bahwa kolagen akan merusak fungsi dan jaringan payudara jika disuntikan ke payudara $(7,10)$.

Setelah responden mengikuti suntik silicone cair dan mengetahui hasilnya (lihat Tabel 6), mereka merasa lebih cantik dan menarik serta lebih percaya diri sesuai yang diharapkan hal ini menunjukkan bahwa sebelum mereka suntik silicone cair mereka kurang percaya diri dengan penampilan sebelumnya. Hal ini tidak terlepas juga dengan gaya hidup responden, berdasarkan hasil penelitian 12 responden atau $60 \%$ menjawab senang dan selalu mengikuti tren kecantikan yang ada seperti suntik silicone cair untuk mempercantik diri maupun mengikuti tren kecantikan lainnya (lihat Tabel 7).

Berdasarkan data-data yang diperoleh dari penelitian bahwa pengguna suntik silicone cair dalam mengambil keputusan atau berperilaku sebelum suntik silicone cair sampai akhirnya mengikuti suntik silicone cair dipengaruhi oleh motivasi baik motivasi yang datangnya dari dalam diri sendiri maupun dari orang lain dan lingkungan. Motivasi internal yaitu faktor kurang percaya diri, merasa dirinya kurang cantik, tidak bersyukur atas pemberian dari Tuhan, faktor pendidikan dan pengetahuan terutama pengetahuan tentang silicone cair dan efek samping silicone cair yang rendah, faktor emosi, kejiwaan untuk tampil lebih cantik, 
lebih percaya diri dan menarik. Sedangkan faktor eksternal meliputi faktor lingkungan yang mendukung untuk mengikuti suntik silicone cair misalnya dukungan dari keluarga (lihat Tabel 4), lingkungan kerja yang mendukung terutama pekerjaan yang menuntut untuk tampil cantik dan menarik (lihat Tabel 7) teman kerja yang menginformasikan tentang suntik silicone cair ini. Lingkungan sosial juga bisa mempengaruhi misalnya perkumpulan yang diikuti responden seperti Iwama (lkatan Waria Malang) ataupun perkumpulan senam dan arisan. Faktor Sosial ekonomi dalam keterkaitan dengan keikutsertaan responden untuk suntik silicone cair ini erat kaitannya dengan keuangan atau penghasilan responden maupun suami atau isteri responden. Hal ini terkait dengan biaya penyuntikkan silicone cair yang relatif mahal. Faktor budaya kaitannya erat sekali terhadap kebiasaan dan perasaan responden untuk tampil cantik, menarik dan percaya diri. Dari motivasi interna dan motivasi eksterna yang mempengaruhi responden untuk suntik silicone cair, maka motivasi eksterna lebih dominan dibanding motivasi interna dalam berperilaku untuk mengikuti suntik silicone cair.

\section{KESIMPULAN}

1. Pengetahuan responden tentang silicone cair rendah, $15(75 \%)$ responden mengetahui kegunaan suntik silicone cair untuk merubah bentuk tubuh agar lebih indah, cantik,menarik dan percaya diri tanpa mengetahui efek samping silicone cair.

2. Tingkat pendidikan responden yang tidak tamat sekolah dasar sampai responden yang tamat Sekolah lanjutan Tingkat Pertama sebanyak7 (35\%) responden sedangkan tingkat pendidikan menengah ke atas sebanyak $13(65)$ responden
3. Pekerjaan responden yang terbanyak adalah sebagai pegawai salon kecantikan sebesar 6 (35\% responden.

4. Perasaan pengguna setelah suntik silicone cair dan tahu hasilnya adalah merasa lebih cantik dan percaya diri sebanyak $9(45 \%)$ responden.

5. Responden yang mendapat dukungan dari keluarga sebanyak $6(30 \%)$ responden

6. Responden yang mempunyai perkumpulan dan berhubungan dengan keikutsertaannya untuk suntik silicone cair adalah $14(70 \%)$.

7. Responden atau Pelayanan kesehatan tingkat primer oleh petugas kesehatan tentang suntik silicone sebanyak $0 \%$, sedangkan pelayanan kesehatan tingkat sekunder sebanyak $5(25 \%)$ responden dan pelayanan kesehatan tingkat tersier sebanyak $4(20 \%)$ responden.

8. Gaya hidup Responden yang selalu mengikuti tren kecantikan yang ada sebanyak $12(60 \%)$ responden.

9. Motivasi eksterna lebih dominan dibanding motivasi interna untuk menggunakan suntik silicone cair.

\section{SARAN}

1. Sebagai bahan masukan bagi institusi kesehatan dalam penyusunan materi penyuluhan kesehatan dalam rangka upaya pencegahan.

2. Sebagai bahan pertimbangan bagi pengguna jasa salon-salon kecantikan yang menawarkan jasa suntik silicone cair mengingat dampak negatif yang dapat terjadi.

3. Bagi Aparat Penegak Hukum untuk dapat memantau praktek praktek yang dapat membahayakan kesehatan masyarakat pada umumnya.

\section{DAFTAR KEPUSTAKAAN}

1. Yosef Herman Lw. Debulking sebagai Penanganan Awal pada Penderita dengan Radang Kronis di Wajah akibat Suntikan Silicone Cair. Makalah Pertemuan IImiah tahunan periode 2001. Malang: Laboratorium IImu Bedah RSSA. 2001: 1,6,7.

2. Jawa Pos, 26 Maret 2001, Disuntik Empat Kali, Payudara Malah Menyamping.

3. Jawa Pos, 12 April 2001, Silicone Maut.

4. Wisataadmadja Sjarif M. Penuntun IImu Kosmetik. Jakarta: UI- Press. 1997: 79.

5. Adisasmito Soenardi. Prinsip-Prinsip dan Metode Epidemiologi, Laboratorium Kesehatan Masyarakat Fakultas Kedokteran Universitas Brawijaya. Malang. 1986: 33.

6. Ahmadi Abu dkk. Psikologi Social. Jakarta: Rineka Cipta. 1991: 191-193.

7. Azrul Azwar. Menuju Pelayanan Kesehatan yang Lebih Bermutu. Jakarta: Yayasan penerbit Ikatan Dokter Indonesia. 1996: 45-48.

8. Denny, Dallas MA. Transgender Youth at Risk for Explaitation, HIV, Hate Crimes. 1995. (http://www.aidsinfonyc.org/qzone/youth.html.trans diakses tanggal 1 Maret 2002).

9. Entjang, Indan. IImu Kesehatan Masyarakat. Bandung. 1997: 15-18.

10. Harding, Anne. Lasers, Silicone can be an Explosive mix. 2001. (http://www.nim.nih.gov/medline plus/news/fullstrory_1289.html. diakses tanggal 20 Mei 2001). 